\title{
Not for publication, de Nadine Gordimer: um estudo sobre a transculturação
}

\section{Not for publication, by Nadine Gordimer: a review about transculturalism}

\author{
Carla Cristina Gaia dos SANTOS* \\ UEM \\ Mario Lousada de ANDRADE** \\ UEM
}

\section{Alba Krishna Topan FELDMAN*** UEM}

Resumo: Nadine Gordimer foi uma renomada escritora sul-africana cujas narrativas denunciam a deterioração social do ser humano que inundou a África do Sul durante o regime do apartheid. Por se tratar de um conturbado período desta ex-colônia britânica, as narrativas de Gordimer abrem espaço para serem amplamente analisadas sob a ótica das teorias Pós-Coloniais, em seus mais diversos enfoques. Este artigo, por sua vez, tem por objetivo refletir sobre a transculturação no conto Not for publication (1965). O termo foi cunhado por Ortiz (1940), redefinido por Rama em meados de 1970 e amplamente utilizado por autores contemporâneos para compreender o choque cultural no momento de encontro de duas culturas diferentes, uma dominada, outra dominante. Compreende-se, portanto, que relações de poder permeiam o encontro de culturas, nunca resultando em trocas culturais simétricas, muito menos passivas. As personagens de Nadine transparecem quão perturbadores e conflituosos tais processos podem ser, bem como evidenciam os problemas sociais e as divergências políticas geradas por tais impasses no contexto sul-africano.

Palavras-chave: Apartheid. Pós-Colonialismo. Transculturação.

\begin{abstract}
Nadine Gordimer was a renowned South African writer whose narratives denounce how the apartheid regime socially influenced South Africans causing social and human decay. Since it is a troubled period of this British excolony, the narratives of Gordimer may be widely analyzed from the perspective of Postcolonial theories in their most diverse approaches. Therefore, this article aims to reflect on transculturation in the short story Not for publication (1965), a term coined by Ortiz (1940), redefined by Rama in the middle of 1970 decade and have been widely used by contemporary authors in order to understand the cultural shock that happens when different cultures come together, usually a dominant and a dominated one. As a result, we may understand that relationships of power permeates cultural encounters, never resulting in symmetrical or passive cultural exchanges. The characters of Nadine transpire how disturbing and conflicting such processes can be and highlight the social problems and political differences generated by such impasses in the South African context.
\end{abstract}

Keywords: Apartheid. Post-Colonialism. Transculturalism.

\author{
* Aluna da Pós- \\ Graduação em Letras \\ com ênfase em \\ Estudos Literários da \\ Universidade Estadual de \\ Maringá, nível Mestrado. \\ E-mail para contato: \\ carlinha_criz@hotmail. \\ com. \\ ***Aluno da Pós- \\ Graduação em Letras \\ com ênfase em \\ Estudos Literários da \\ Universidade Estadual de \\ Maringá, nível Mestrado. \\ E-mail para contato: \\ mario_lousada@hotmail. \\ com. \\ *** Professora Doutora \\ da Pós-Graduação em \\ Letras com ênfase em \\ Estudos Literários da \\ Universidade Estadual \\ de Maringá. E-mail para \\ contato: profa.alba@ \\ gmail.com.
}




\section{Introdução}

Nadine Gordimer nasceu em Spring, uma pequena província ao leste Johanesburgo em 20 de novembro de 1923 e faleceu em julho de 2014, aos 91 anos. Quando criança, foi proibida pela mãe de frequentar a escola ou de praticar qualquer outra atividade ao ar livre. Nixon (1992), ao escrever a biografia da autora, conta que a mãe de Nadine, miseravelmente mal casada, se apaixonara pelo médico da família e usou uma simples tireoide descoberta na filha aos 11 anos de idade para impulsionar seu relacionamento nunca consumado. O resultado foi uma criança sem amigos, sem formação escolar, mas que encontrou na companhia dos livros uma alternativa de refúgio ao egoísmo da mãe e à companhia dos adultos da casa.

Apesar de não ter frequentado a escola e não ter qualificações legais para cursar uma universidade durante a juventude, Nadine dominava proficientemente as formas e convenções da escrita literária, o que lhe proporcionou ser, ainda hoje, uma das escritoras sul-africanas que mais publicou durante a vida. Nixon (1992, p. 9) relembra que, devido ao seu domínio das técnicas narrativas, Nadine considerava a si mesma uma escritora de estilo andrógeno, como confessa em uma introdução de sua coletânea Selected Stories, publicada em Londres no ano de 1975. Isso porque, em suas narrativas, Gordimer flutuava livremente dentre as mais diversas focalizações e pontos de vistas, por vezes vagando entre narradores e personagens masculinas ou femininas.

Durante toda sua trajetória, Nadine escreveu nove romances, mais de 200 contos e inúmeros ensaios políticos e literários, cujos temas abrangem principalmente a deterioração do social e humano que inundou a África do Sul durante o período do apartheid. Suas narrativas são conhecidas mundialmente pelo caráter ativista que reforça a cultura de resistência contra a censura, o racismo e a segregação dominantes naquele espaço. Até o final de sua vida, a escritora acumulou nove títulos de doutor honoris causa de universidades espalhadas por toda a Europa.

Percebe-se nas histórias de Gordimer sua aguçada sensibilidade ao descrever a condição subalterna e diminuída dos negros, partindo de uma escrita leve, porém incisiva. Tal fato fez com que a autora fosse mundialmente lida, mas censurada dentro de seu próprio país. Por conta de seu intenso engajamento político e social em denunciar as angústias e dualidades humanas durante um período tão conturbado da história da África do Sul, ex-colônia dos bretões, as narrativas de Gordimer abrem espaço para serem amplamente analisadas sob a ótica das teorias Pós-Coloniais, em seus mais diversos enfoques. Este artigo, por sua vez, terá como objetivo refletir sobre a transculturação no conto Not for publication que, apesar do título sugestivo, foi publicado em 1965 em uma coletânea homônima. 


\section{Transculturação}

Em 1940, Fernando Ortiz publica o ensaio Contrapuento cubano del tabaco y del azúcar, considerado ainda hoje uma das mais importantes obras da identidade nacional de Cuba. Partindo de seu interesse em compreender a cultura afro-cubana desenraizada do continente africano, o antropólogo se utiliza dos dois principais produtos da economia local, o açúcar e o tabaco, para tecer uma representação dos paradoxos e oposições que perpassavam a organização sociocultural do país. Apesar do tom poético e irreverente das alegorias narradas pelo autor ao contrapor esses dois elementos, o livro apresenta de maneira muito real os problemas da dinâmica de formação econômica e cultural cubana. Além da originalidade com que trata a história econômica de seu país, Ortiz também introduz um novo termo ao vocabulário das ciências humanas: transculturação.

Ao traçar uma linha da formação do povo cubano, Ortiz afirma que o resultado advinha da mescla entre diversos povos indígenas, nativos da região, seguido pela mistura com os europeus até a chegada dos negros africanos. Os choques entre essas diversas culturas nos diferentes períodos históricos são muito mais complexos do que o termo "aculturação" - que estava em voga naquele momento - poderia expressar. Tal como propõe:

(...) as fases do processo de transição de uma cultura a outra, já que este não consiste somente em adquirir um cultura diferente, como sugere o sentido estreito do vocábulo anglo-saxão “aculturação” mas implica também necessariamente a perda ou desligamento de uma cultura precedente, o que poderia ser chamado de uma parcial desculturação, e, além disso, significa a consequente criação de novos fenômenos culturais que poderiam ser denominados neoculturação. (ORTIZ, 2000, p. 90)

Diferentemente de aculturação, que compreenderia apenas imposição da cultura dominante ao indivíduo alterizado, como se uma cultura pudesse ser simplesmente substituída por outra, o termo proposto por Ortiz abarca todo o processo de choque cultural, compreendendo a situação como um fenômeno sempre em movimento. O sociólogo não compreende este fenômeno como um momento de assimilações pacíficas. Ao contrário, trata-se de um processo doloroso de perdas e ganhos para ambas as partes envolvidas. Contudo, Ortiz reconhece que dentro do contexto de construção histórica cubana, os negros foram os maiores prejudicados por conta da condição de extrema vulnerabilidade frente ao sistema escravocrata que os transplantou para fora do continente africano.

Dessa forma, Reis (2012), ao resenhar sobre o tema, comenta que para o autor,

(...) a necessidade do neologismo proposto é vital, pois não há nenhum outro fenômeno de maior transcendência na formação histórico-social do 
povo cubano que a mestiçagem, e esta não pode ser entendida sem um conceito teórico que lhe dê sustentação, pois a noção de transculturação ultrapassa a visão limitada de mestiçagem racial, para significar o movimento que subjaz ao encontro de culturas. (REIS, 2012, p. 468)

O conceito de Ortiz passou a ser incorporado por diversas áreas de pesquisa dentro do âmbito dos estudos culturais, sociológicos e literários, sofrendo reapropriações e novas leituras desde então. Exemplo notável disso é a contribuição do uruguaio Ángel Rama em seu artigo Os processos de transculturação na narrativa latino-americana (2001), no qual ele se apropria do conceito acima exposto aplicando-o ao campo crítico literário com o intuito de compreender os desacordos e acordos entre o vanguardismo modernista do século XX e o regionalismo.

De acordo com Rama (2001), os regionalistas passaram por três momentos de desenvolvimento literário frente à pressão modernizadora estrangeira. Inicialmente, houve a aceitação das novas formas. Contudo, o que se seguiu foi um momento de recusa e rigidez, causado pelo choque e o intuito de resguardar seus valores. Um terceiro momento culmina na necessidade de sobrevivência, marcado pela integração das novas formas sem recusar-se por inteiro as tradicionais. A este terceiro momento, Rama denominou "plasticidade cultural", sendo a peça-chave da sua teoria de narrativa de transculturação. Apesar de concordar com a concepção de processo incorporadas por Ortiz, Rama discorda que se trate de fenômeno geometricamente simétrico, no qual o momento de desculturação parcial pode, segundo ele, ter diferentes níveis e alcançar diferentes zonas culturais.

Reis (2012) compreende que para Rama, o conceito cunhado por Ortiz "não atende adequadamente nem aos critérios de seleção, nem aos de inventividade, postulados obrigatórios em todos os casos de 'plasticidade cultural', uma vez que eles legitimam a energia e a criatividade de uma comunidade” (REIS, 2012, p. 471). Ou seja, Rama, seguindo sua concepção de narrativas de transculturação, defende que a "plasticidade cultural”, fruto do choque entre duas culturas, caracteriza o movimento de neoculturação como uma resposta criativa das culturas alterizadas contrapostas ao centro dominante. Não se trata apenas de violência e perdas, mas também de um enriquecimento paradoxal, responsável por transformar a cultura dominada.

Como discorre Reis (2012), o conceito de transculturação, tal qual cunhado por Ortiz e reformulado por Rama, sofre também críticas de diversos teóricos e estudiosos das áreas envolvidas, entre eles Alberto Moreiras, Jhon Beverly e o alemão Friedhelm Schmidt. De acordo com a pesquisadora, as críticas caminham no sentido de que as culturas dominantes também sofrem modificações e reformulações quando postas em contato com as culturas dominadas, além de criticarem aquilo que Rama denomina de transculturação bem sucedida, ou seja, quando a cultura dominada se 
reformula de tal maneira, a ponto de se inscrever na cultura dominante. Para a estudiosa, "essa posição de Rama sugere um forte posicionamento ideológico, pois implica na aceitação da modernização como uma verdade ideológica e destino do mundo, uma auto sujeição histórica à modernidade eurocêntrica”. (REIS, 2012, p. 483)

Mary Louise Pratt (1999), por sua vez, parte dos pros e contras da concepção conceitual de transculturação discutidas até então, para compreender as modificações que tal fenômeno acarreta ao imaginário europeu. Para tanto, ela se debruça sobre relatos de viagem e cunha um conceito próprio para tratar do espaço onde ocorrem os choque culturais, denominados "zonas de contato":

(...) uso para me referir ao espaço de encontros coloniais, no qual as pessoas geográfica e historicamente separadas entram em contato umas com as outras e estabelecem relações contínuas, geralmente associadas a circunstâncias de coerção, desigualdade radical e obstinada. Aqui, tomo emprestado o termo "contato" de seu uso em linguística, onde a expressão "linguagem de contato" se refere a linguagens improvisadas que se desenvolvem entre locutores de diferentes línguas nativas que precisam se comunicar entre si de modo consistente, um com o outro, usualmente no âmbito comercial. Tais linguagens surgem como jargões, e são consideradas crioulas quando chegam a ter falantes nativos de seu próprio lugar. Como as sociedades das zonas de contato, tais linguagens são normalmente consideradas caóticas, bárbaras e amorfas. (PRATT, 1999, p. 32)

Partindo desta concepção, Pratt (1999) evidencia o fenômeno da transculturação enquanto um processo de construção identitária subjetiva que se desenrola a partir da interatividade e do confronto entre as partes envolvidas. Compreende a tensão que se estabelece entre colonizadores e colonizados, dominantes e dominados, não como bipolarização e segregação, mas sim “em termos da presença comum, interação, entendimentos e práticas interligadas, frequentemente dentro de relações radicalmente assimétricas de poder”. (PRATT, 1999, p. 32)

Concordâncias e contradições a parte, nos valeremos do termo transculturação em sua amplitude conceitual, para nos referir ao encontro de duas culturas diferentes que interagem no mesmo espaço, provocando reflexões sócio-críticas sobre as tensões e relações de poder que entram em jogo nesse espaço de interatividade cultural e subjetiva, tal qual é despertado pelo conto Not for publication, de Nadine Gordimer (1965). A narrativa transparece o espaço de transculturação que envolve os nativos sul-africanos e os brancos descendentes da colonização britânica, cuja convivência resultou em um dos regimes mais cruéis de discriminação racial na história da humanidade. 


\section{$O$ conto $^{1}$}

O conto Not for publication, de Nadine Gordimer (2004), se passa na África do Sul, mais especificamente em Johannesburgo. Segundo Zanoto et al (2010), desde $1884 \mathrm{com}$ a descoberta do ouro na região do Estado do Transvaal, a cidade é considerada o centro econômico do país, o que possibilitou aos britânicos se equilibrarem econômica e politicamente com os bôeres, descendentes dos primeiros holandeses que lá se instalaram. A narrativa, entretanto, se passa já em meados do século $\mathrm{XX}$, período no qual as políticas segregacionistas do apartheid se destacavam. O conto é centrado na infância e adolescência de Praise Basetse, uma personagem identificada como atual Primeiro Ministro do Protetorado britânico. Apresenta-se logo de início como um capítulo não publicado e não divulgado de suas biografias oficiais, deixando subentendido a ideia de que trará passagens de sua trajetória não orgulhosamente associadas à sua imagem pública.

Praise era um menino negro que mendigava nas ruas de Johannesburgo junto com seu velho tio, ajudando-o a se desvencilhar dos carros nas ruas e guiando-o para todos os lados, já que o velho "não era totalmente cego mas, sem dúvida, era louco"2 (GORDIMER, 2004, p. 112). Eles andavam boa parte do dia, mas com o tempo, fixaram-se num lugar próprio, próximos à banca de cadarços e pulseiras de cobre, e entre o perneta e o outro sujeito com bracinho de boneca. Procuravam sempre um lugar ao sol, pois, segundo o garoto, lá as esmolas eram mais fartas. Aprendera quase tudo nas ruas, desde a ler com os pôsteres das bancas de jornais até a enrolar o cigarro de maconha que fumava apenas por diversão, assim como faziam os meninos mais velhos quando não estavam roubando as bolsas das mulheres brancas ou arrumando uma maneira de escapar dos policiais.

Em um dia não muito diferente dos demais, Senhorita GrahamGrigg passa por eles e ao remexer a bolsa em busca de algumas moedas para o chapéu do velho, percebe que eram membros de uma tribo na qual ela própria já se instalara por parte do Protetorado britânico. Apesar de não saber muito bem o idioma dos nativos ela reconheceu a língua na qual o velho murmurava e sentiu-se ainda mais movida à ajudá-los. Compreendeu a recusa inicial do velho em responder suas perguntas, já que um negro nativo como ele enfrentaria muitos problemas com a fiscalização caso fosse descoberto irregular ali naquele território. Mesmo assim, ela conseguiu cuidar dos direitos pensionistas do tio e não teve problemas para adotar Praise, já que ninguém sabia ao certo quem eram seus pais. Ele era, possivelmente, filho de uma das meninas da família.

Já de início o conto nos remete à realidade sul-africana do início do século passado, na qual os negros eram proibidos de andarem por certas ruas e regiões do país. Sabe-se que a segregação foi ainda mais intensa,
${ }^{1} \mathrm{O}$ conto Not for publication, de Nadine Gordimer (2004), não se encontra traduzido para a língua portuguesa. As citações retiradas dele foram livremente traduzidas pelos autores e os excertos em língua fonte citados em notas de rodapé sempre que necessário.

\footnotetext{
2 "His uncle was not really blind, but nearly, and he was certainly mad.” (GORDIMER, 2004, p. 112)
} 
se estendendo para quase todos os ambientes públicos, desde banheiros, meios de transportes, como ônibus, trens, até bibliotecas, praias e parques. Tudo respaldado pela Lei do Passe, na qual o negro era obrigado a carregar consigo uma caderneta dizendo por quais locais poderia andar. Eles podiam ser abordados em qualquer lugar, a qualquer horário, sempre que a fiscalização julgasse necessário.

A senhorita Adelaide Graham-Grigg era londrina, filha de um antigo parlamentar britânico e neta de um bispo. Estava na cidade por parte do Protetorado, apesar de sonhar com a independência sul-africana e acreditar no dia no qual as tribos seriam fortes o suficiente para reunirem todos seus exilados e desenvolverem "seus próprios sistemas democráticos ao invés de resignarem-se ao sistema ocidental”3 (GORDIMER, 2004, p. 121). O fato de Adelaide ser nascida e educada de acordo com os altos moldes britânicos e ainda assim rebelar-se contra a organização segregacionista que se instalara ao sul da África revela desde o princípio sua identidade transculturada pela vivência em meio aos nativos.

Ela levou Praise de volta à tribo para morar com ela, lhe deu roupas limpas e o matriculou na escolinha local, ao invés da escola missionária. $\mathrm{O}$ menino era brilhante, em pouco tempo já conseguia soletrar perfeitamente, coisa que os garotos de dezesseis ou dezoito anos ainda apresentavam dificuldades. Rapidamente foi transferido da turma de iniciantes para a turma de nível três e, cerca de dezoito meses depois, já havia completado os conteúdos programáticos do nível cinco. A moça se espantava cada vez mais com as habilidades dele, que a esta altura estava apenas um ano atrás da idade média das crianças brancas da cidade, ainda que essas contassem com a vantagem de serem nascidas e criadas em meio a famílias letradas.

Rapidamente a escolinha da tribo não tinha mais nada a oferecer, pois ainda não havia ninguém suficientemente preparado para avançar ao nível seis. Mas a ideia de enviá-lo a uma escola missionária não a agradava. Adelaide não suportava a maneira como os missionários se utilizavam da crucificação de Cristo para condicionarem os africanos aos costumes e normas ocidentais. Ela não partilhava das mesmas convicções e ideologias desses grupos, por isso decidiu que a melhor opção seria a escola do Padre Audry, um anglicano que também não aceitava as diferenças raciais que perpetuavam ao sul da África, “embora as bases de suas recusas muitas vezes divergissem”" (GORDIMER, 2004, p. 119)

Adelaide tinha intenções maiores para o futuro do garoto, como disse ao Padre Audry, ao levá-lo à sua escola: ela não podia deixar que ele viesse a se tornar um sacerdote, pois a tribo precisava dele de volta. Pouquíssimos lá possuíam educação e em poucos anos, quando a independência chegasse, eles precisariam de pessoas instruídas que pudessem governar. Audry aconselhou a senhorita a levá-lo a outra escola, dirigida pelo Padre Chalmon e que contava com um dos mais atualizados sistemas
3 “(...) develop their own tribal democracy instead of taking over the Western pattern." (GORDIMER, 2004, p. 121)

4 “"(...) however different the bases of their rejection." (GORDIMER, 2004, p. 119) 
de ensino da região. Mas Adelaide rebate ferrenha: “Jamais o confiaria àquelas pessoas', disse espirituosamente, requerendo que ele se lembrasse o que ela pregava quanto aos missionários e o papel que eles desempenhavam na África"5 (GORDIMER, 2004, p. 121)

Padre Audry então acolhe Praise e também se surpreende com tamanha capacidade do garoto. Ele destacava-se dentre todos, seu inglês era invejável, sua escrita impecável. Praise não era como os outros "garotos africanos de calibre menor, que, pela visível falta de um background cultural, encontravam dificuldade em resolver um exercício conhecido por eles, mas apresentado de forma diferente daquela apresentada nos livros didáticos”6 (GORDIMER, 2004, p. 127). Praise era bom, esforçado e estudioso. Os padres da escola, juntamente com Adelaide, começaram a sonhar com a possibilidade do primeiro negro sul-africano a entrar para uma universidade inglesa, como Cambridge ou Oxford. Era um triunfo para o garoto, para a escola e para todos os outros considerados inferiores por conta do padrão educacional africano.

Todos apostaram alto no garoto, Padre Audry, Irmão George, Adelaide. Todos se entusiasmaram com as possibilidades e as portas que poderiam ser abertas por Praise. O garoto começou a ser cobrado, pressionado, deveria estudar como nunca houvera antes:

Irmão George sempre o perguntava se ele estava cansado. Mas não estava cansado. Apenas queria ficar com seus livros. Os garotos do dormitório pareciam saber disso, pois nunca mais o chamaram para jogar cartas. Mesmo quando compartilhavam fumaça no banheiro, eles lhe passavam a bituca em silêncio. (...) Ele iria sempre repousar sua bochecha nos livros, sozinho com seus estudos. Era tudo que lhe restara. (GORDIMER, 2004, p. 126) ${ }^{7}$

Praise era bom no que fazia, mas se sentia sozinho, afastado dos outros alunos e colegas da sua idade. A pressão era tamanha, pois todos esperavam que conseguisse uma bolsa na Inglaterra, que entrasse para os Rhodes Scholars, que continuasse surpreendendo. Ele era negro, nativo, mendigo das ruas de Johannesburgo, que com a ajuda e educação proporcionados pela Senhorita Graham-Grigg e pelos padres professores, estava tendo a oportunidade de subverter a posição inferiorizada relegada aos negros em seu próprio país. Ainda que de maneira velada, pois Praise era apenas um jovem, agora no auge dos seus quinze anos, sem amigos ou família, representava o momento de apropriação da cultura ocidental como forma de subversão e resposta ao centro dominante. Mas a pressão foi tão intensa que uma crise histérica se apoderou do garoto, culminando em sua fuga pouco tempo antes dos exames classificatórios.
5 “I wouldn't send him to those people', she said spiritedly, implying that he knew her views on missionaries and their role on Africa." (GORDIMER, 2004, p. 121)

6 “(...) African boys of a lesser calibre the inability, through lack of na assumed cultural background, to perform a piece of work well known to them, once it was presented in a slightly different manner outside one of their own textbooks(...)" (GORDIMER, 2004, p. 127)

\footnotetext{
7 "Brother George often asked him if he were tired. But he was not tired. He only wanted to be left with his books. The boys in the hostel seemed to know this; they never asked him to play cards any more, and even when they shared smokes together in the lavatory, they passed him his drag in silence. (...) He would rest his check against the pages of the books, now and then, alone in the study; that was all." (GORDIMER, 2004, p. 126)
} 


\section{A África do Sul como zona de contato e espaço transculturado}

A narrativa de Nadine transparece de maneira nada inocente o contexto de marginalização e hostilidade que perpassavam a vida dos negros. O continente africano desde muito cedo teve seu povo subjugado e suas manifestações culturais violentadas pelo imperialismo europeu. Desde a chegada dos primeiros povoadores brancos a dominação das populações autóctones se deu de maneira brutal e plenamente justificada pela doutrina de salvação e de predestinação, pregada desde sempre pelos povos europeus e reafirmada por seus missionários.

Segundo Ashcroft et al (1989, p. 8), existiram três tipos de colônias: as de povoadores, a de sociedades invadidas e as sociedades duplamente invadidas. $\mathrm{O}$ continente africano é visto pelos pesquisadores como uma colônia de segundo tipo, na qual o território foi tomado pelos europeus, sua população escravizada e dizimada em seu próprio espaço geográfico, sua língua e cultura colocada em alteridade.

A Bíblia, desde os tempos mais remotos, foi utilizada como alicerce da dominação territorial e cultural dos povos indígenas e africanos. Utilizando-se de sua suposta superioridade intelectual, cultural e espiritual, os europeus se sentiam no dever de levar às essas pessoas a civilização, o progresso, a educação, a religião. Subjugando e obrigando tais sociedades a se organizarem como as suas próprias, a falarem e a orarem como eles mesmos faziam. Nenhum outro tipo de deus, de organização social ou língua era considerada civilizada o bastante. Nenhuma outra forma de arte era considerada, de fato, arte.

Adelaide Graham-Grigg, personagem do conto de Gordimer, compreendia a violência com que a cultura africana era tratada pelos britânicos, mas não percebia que ela fazia o mesmo, ainda que com intenções opostas. Por mais que morasse na tribo, trabalhasse nas plantações com as outras mulheres e acreditasse no potencial de desenvolvimento dos africanos após a independência, ela também repudiava os nativos que não se adequavam aos modelos culturais ocidentais fortemente enraizados em sua percepção. Quando o Padre Audry lhe sugeriu que talvez fosse bom para Praise reatar as relações com sua família, ela rapidamente respondeu: "Eles são horríveis"8 (GORDIMER, 2004, p. 121)

A família do garoto era nativa de uma das tribos dos entornos de Johannesburgo e, como muitas outras famílias, se viam tentadas a partir para a cidade, o “centro da civilização”. Chegando lá, tinham costumes diferentes, hábitos e rotinas que não podiam se sustentar no "novo” cenário social. Ficavam condicionados a condições de moradias precárias, à saúde deficiente, à alimentação fraca e à educação ainda pior. Tratava-se de pessoas que não tinham condições básicas de manterem uma vida compatível com os valores disseminados pelo modo de viver da cultura ocidental. 
Adelaide, por sua vez, assume o papel de mãe do garoto e oferece a Praise todas as possibilidades desse modo de vida até então inatingível. Oferece-lhe a oportunidade de ser tão bom quanto uma criança branca da cidade. Mas ser bom naquele contexto significaria dominar bem o inglês, escrever bem e corretamente, ou seja, ser educado e ter um bom progresso de acordo com os conteúdos e conhecimentos disseminados pela metrópole britânica, a fim de conseguir garantir uma vaga em uma universidade inglesa.

Apesar de ter boas intenções e querer apenas o bem do garoto, Adelaide cumpre, em um primeiro momento, a função de levá-lo a luz e o conhecimento acumulado pelas nações europeias, com os moldes culturais europeus, desprezando o conhecimento que já estava presente na tribo e em suas tradições. Com o desenrolar da narrativa, esse papel é gradativamente assumido pelo Padre Audry. Este, além de passar ao garoto os ensinamentos regulares da escola, também lhe ensinou sua religião. De acordo com o texto, Praise cantava no coral da igreja e "aos domingos acompanhava as outras crianças à celebração, apesar da Senhorita Graham-Grigg ter-lhe dito que não era necessário"9 (GORDIMER, 2004, p. 117). A religião, por meio de elementos como escolas de ensino às crianças e catequização, é um dos instrumentos mais efetivos de imposição cultural. Audry também ensinou o menino a tocar flauta e a escutar música não apenas por diversão ou prazer, mas para que compreendesse os elementos de composição e ritmo. Para isso se valia das melodias de Bach.

Praise aprendia tudo isso com muita rapidez e eficiência, mas não de maneira passiva. Ainda que na sua inocência de criança, ele percebia as relações de poder que se estabeleciam nessa convivência:

Com seu short azul-marinho e camiseta branca que compunha o novo uniforme da escola, entrou Praise porta adentro. A bondade dela e a atenção dele voltados para ele o faiscavam do mesmo jeito que o sol quando ardia contra o cocho onde os bois iam beber água. Segundo a Senhorita GrahamGrigg, Padre Audry tinha vindo da Inglaterra, assim como ela. Eles eram assim, embora, não se parecessem em nada com os outros brancos que o garoto conhecia. Eles estavam justamente sendo ingleses. Mesmo com toda a distância, com todos os 10 mil quilômetros que os separavam daquela terra - era o que dizia seu livro de geografia. (GORDIMER, 2004, p. 121$122)^{10}$

Podemos compreender toda a ambientação descrita até o momento como a zona de contato entre a cultura inglesa e sul-africana representadas pelas três personagens centrais: Adelaide, Padre Audry e Praise. Ou seja, trata-se de "espaços sociais onde culturas díspares se encontram, se chocam, se entrelaçam uma com a outra” (PRATT, 1999, p. 27), pois, apesar de representarem duas culturas opostas, também representam identidades interagentes e transculturadas.

\footnotetext{
9 “Though Miss

Graham-Grigg had said he need not, he went to church with the children on Sundays.” (GORDIMER, 2004, p. 117)
}

10 "Praise entered in the navy blue shorts and white shirt of his new school uniform. The woman's kindness, the man's attention, got him in the eyes like the sun striking off the pan where the cattle had been taken to drink. Father Audry came from England, Miss Graham-Grigg had told him, like herself. That was what they were, these two white people who were not like any white people he had seen to. What they were was being English. From far off; six thousand miles from here, as he knew from his geography book." (GORDIMER, 2004, p. 121-122) 
Grande parte do conto é dedicada a narrar como Praise estava sendo educado e preparado para conseguir sua bolsa universitária, passagens estas que podemos associar ao que as teorias conceituais apresentadas anteriormente classificariam como uma parcial desculturação, rumo à hibridez resultante da posterior neoculturação. Praise sofre as tensões desse choque cultural e de todo o processo pelo qual está passando. Basta olhar para a descrição das roupas do menino apresentada logo acima: uma criança sul-africana originária de uma das tribos nativas vestindo o uniforme composto de shorts azul-marinho e camiseta branca.

Outra passagem que podemos nos valer para compreender a identidade transculturada do garoto, se refere ao dia no qual Adelaide vai visitá-lo na escola e leva-lhe notícias de seus amigos da tribo, Tebedi, Joseph e os outros, "mas quando ele escutou aqueles nomes, parecia que não conseguia mais se lembrar daquela gente"11 (GORDIMER, 2004, p. 123), da qual ele fazia parte. Partindo das lembranças difusas, percebemos o desligamento de Praise a sua cultura anterior. Contudo, não se pode afirmar que há um afastamento total, pois como a própria personagem reflete, jamais se esqueceria do tio e da "pequena inclinação que o peso da mão do velho lhe deixara nos ombros"12 (GORDIMER, 2004, p. 123).

Depreendemos, dessa maneira, que por maior que seja o afastamento de Praise de sua cultura e amigos nativos, ele não a esquecera, apenas a transformara. Ao relembrarmos que este mesmo garoto se tornara no futuro fictício criado pela narrativa um Primeiro Ministro, compreendemos que o contato entre as duas culturas não atingiu seu resultado por conta de uma dinâmica aditiva, sendo uma cultura adicionada à outra, mas ambas transfiguraram-se em algo novo, diferente do que existia anteriormente.

Embora haja esse embate em que culturas díspares entram em uma relação de poder e sejam colocadas de forma desigual, não é apenas a identidade marginalizada que sofre modificações. A própria Adelaide é resultado do processo e do espaço transcultural no qual está inserida. Tratase de uma personagem britânica, criada segundo os moldes e convenções europeias, cuja identidade se encontra transformada pelo contexto cultural e segregacionista sul-africano. Em várias passagens, Praise pode ser observado tentando compreender o comportamento paradoxal da moça, pois

Embora nunca houvesse conhecido outra mulher branca antes, a não ser aquelas que passavam apressadas pelas ruas em saltos-alto, ele não acreditava que todas as brancas fossem como ela. De acordo com tudo que havia visto sobre os brancos, com seus carros, muito dinheiro, sempre distantes, ele ficava confuso com tudo o que ela fazia por ele. Ela se parecia com eles, com olhos azuis, cabelos loiros, a pele que era não de uma cor, mas várias: por vezes morena onde o sol queimava ou vermelha quando corava. Mas ela morava na tribo, dirigia para o Chefe e, algumas vezes, dormia fora
11 “(...) but when he heard their names they seemed to belong to people he couldn't see in his mind." (GORDIMER, 2004, p. 123)

12 “(...) he had never grown out of the slight stoop of the left shoulder where the weight of the old man's hand had impressed the young bone." (GORDIMER, 2004, p. 123) 
com as outras mulheres durante as colheitas de milho, distantes da vila. Ele não sabia por que ela o trouxera ou porque era tão amável com ele. Mas ele não podia perguntar-lhe tais coisas, não podia perguntar-lhe porque ela saia e ia dormir nas plantações com as outras mulheres, sendo que ela tinha um gramofone e uma adorável lamparina a gás em seu quarto, a qual ele já tivera a oportunidade de consertar certa vez. (GORDIMER, 2004, p. 118) ${ }^{13}$

Mesmo em sua inocência de criança, Praise percebe as discordâncias entre Adelaide e os demais brancos. Assim como a personagem do garoto, a personagem da moça também não é totalmente desligada de sua cultura anterior, mas é transformada pelo contato de ambas:

Ele (Padre Audry) estava cansado e o esforço para se manter acordado era tamanho, que seu rosto por vezes se contorcia em caretas de concentração enquanto falava com a senhorita Graham-Grigg. Mesmo assim, ela sentia, internamente, um enorme desconforto em sua companhia. Tudo nele era muito certo, muito bem feito. Nela nem tudo. Tinha penas trinta e seis anos, mas nunca tivera aparência jovial. Seus olhos brilhavam como os olhos de uma jovem, mas suas mãos e pés tinham unhas grosseiras, que carregavam a tensão e o sofrimento de extremidades corporais nunca antes bem cuidadas: ela percebia isso e sabia que os distinguiriam sempre. (GORDIMER, 2004, p. 120) ${ }^{14}$

A personagem de Audry, entretanto, constrói-se enquanto alegoria de uma identidade endurecida em sua tradição de cultura dominante e, portanto, menos afetada que as demais. Sabe-se que a personagem não era conivente com as políticas segregacionistas do sul da África, mas sua aparência e comportamento não são afetados pela presença e convivência na zona de contato como as demais personagens, bem como não o é sua posição sacra de líder religioso. Os traços fortes e o porte galante do padre anglicano são mantidos pela imponência da batina negra e pelo peso do terço de madeira carregado à cintura.

A zona de contato onde as três personagens principais circulam acaba por construir cada uma delas a partir da interação e do relacionamento que estabelecem entre si. Tal relacionamento, entretanto, é controlado por relações hierárquicas e assimétricas de poder, as quais limitam e regulam o grau de envolvimento e as consequentes marcas transculturais presentes em cada momento do processo, causando tensões e coerções visíveis para cada uma das partes envolvidas.

Contudo, quem mais sofre o impacto desse choque de culturas é o próprio Praise, cuja posição de protegido e ao mesmo tempo agente, tem de aprender a contrabalançar tensões e repressões trazidas à tona pelo jogo interacional presente na trama. Quando Adelaide o adota, tudo se faz novo e interessante, como a nova escola, a nova cuidadora, as novas roupas, o novo cheiro. Contudo, conforme o garoto vai sendo envolvido pelas
13 "Although he had never known any White women before except as high-heeled shoes passing quickly in the street, he did not think that all white women must be like her; in the light of what he had seen white people, in their cars, their wealth, their distance, to be, he understood nothing that she did. She looked like them, with her blue eyes, blonde hair, and the skin that was not one colour but many: brown where the sun burned it, red when she blushed - but she lived in the Chief's house, drove him in his car, and sometimes slept out in the fields with the women when they were harvesting kaffircorn far from the village. He did not know why she had brought him there, or why she should be kind to him. But he could not ask her, any more than he would have asked her why she went out and slept in the fields when she had a gramophone and a lovely gas lamp (he had been able to repair it for her) in her room.” (GORDIMER, 2004, p. 118)

14 "He was tired and closed his eyes in a grimace straining at concentration when he talk to her, yet in spite of this, she felt the dimness of the candle of her being within his radius. Everything was right with him; nothing was quite right with her. She was only thirty-six but she had never looked any younger. Her eyes were the bright shy eyes of a young woman, but her feet and hands with their ridged nails had the look of tension and suffering of extremities that would never caress: she saw it, she saw it, she knew in his presence that they were deprived forever.” (GORDIMER, 2004, p. 120) 
situações, medos e receios vão surgindo. Primeiro, o ritual de iniciação da tribo lhe tira o sossego: não sabe como contar a Senhorita GrahamGrigg sobre ele, talvez o chefe lhe conte, talvez as mulheres com quem ela ia para colheita. Mas e se contassem, teria ele que abandonar a nova vida na escola do Padre Audry para participar junto com Tebedi, Joseph e os outros? Como se não bastasse, havia ainda a cobrança de todos à sua volta para que fosse sempre melhor, e conseguisse a bolsa de estudos na Inglaterra. E se não conseguisse, qual seria a reação do Padre Audry, do Irmão George e da Senhorita Graham-Grigg?

A fuga do menino ao final da narrativa representa não apenas seu medo do fracasso futuro, mas também seu medo do retrocesso. Tratava-se de um garoto negro que havia experimentado uma nova realidade, cuja permanência naquele círculo, ao que tudo indicava, dependia de ser sempre o melhor. A transculturação ocorreu, portanto, exatamente como o visto anteriormente: a tentativa da tradição em sobreviver a uma cultura dominante, que tenta destruí-la, ambas formando uma terceira cultura, híbrida das duas formas anteriores.

\section{Amarrações e considerações finais}

Paul Gilroy, em sua obra O Atlântico Negro (2001), cria uma alegoria entre a identidade negra e "a imagem do navio", enquanto "sistema vivo, microcultural e micropolítico em movimento” (GILROY, 2001, p. 38). Para o estudioso, a identidade do negro não é nunca homogênea, nem mesmo fixa ou presa a um espaço geográfico único, visto que desde os primórdios das expansões marítimas europeias ela se transforma a partir das trocas culturais feitas por meio do Atlântico, num movimento contínuo de idas e vindas, modificando-se e sendo modificada.

A partir da reflexão sobre o conto de Nadine Gordimer, compreendemos que as zonas de contato onde ocorrem o fenômeno de transculturação se dão muito enfaticamente no próprio solo africano. Percebemos claramente que o Atlântico não apenas é rota de ida dos negros para os outros continentes, como também é rota de vinda dos britânicos para a África do Sul, resultando em identidades complexamente heterogêneas devido às constantes tensões provocadas pelos encontros entre culturas tão diferentes.

Contudo, relações de poder controlam e manipulam tais interações, limitando em maior ou menor grau o envolvimento e o distanciamento, bem como a aceitação e a recusa das diversas partes envolvidas no processo transcultural. Não se trata portanto, de trocas simétricas, muito menos passivas. As personagens de Nadine transparecem quão perturbadores e conflituosos tais processos podem ser, bem como evidenciam os problemas sociais e as divergências políticas geradas por tais impasses no contexto sul-africano. 


\section{Referências}

ASHCROFT, B.; GRIFFITHS, G.; TIFFIN, H. The empire writes back: theory and practice in post-colonial literatures. London: Routledge, 1989.

GILROY, P. O Atlântico Negro. São paulo: Ed. 34, 2001, p. 33-100.

GORDIMER, N. Burger's Daughter. London: Penguin Books, 1979.

. Not for publication. In: BONNICI, T. (org.). Short Stories: an anthology for undergraduates. Maringá: Eduem, 2004.

NIXON, R. Nadine Gordimer. In: British Writers: Supplement 2. New York: Ed. George Stade, 1992.

ORTIZ, F. Contraponto cubano do tabaco e do açúcar. São Paulo: Ed. UNESP, 2000.

PRATT, M. L. Os olhos do império. Bauru: USC, 1999, p. 23-38.

RAMA, A. Literatura e Cultura na América Latina. In: AGUIAR, F.; VASCONCELOS, S. G. T. (org.). Ensaios Latino-americanos. São Paulo: Ed. USP, 2001.

REIS, L. F. Transculturação e transculturação narrativa. In: FIGUEIREDO, E. (org.) Conceitos de Literatura e Cultura. Juiz de Fora: Ed. UFJF, 2012.

ZANOTO, D. S.; GARCIA, J.; BECK, J. O.; QUINSANI, R. H. África meridional inglesa: das estruturas coloniais ao desenvolvimento econômico, político e social no século XX. In: Revista Historiador. n. 03. Dez./2010. Disponível em: < http://historialivre.com/revistahistoriador $>$. Acesso em: 02 set. 2014.

Enviado: 30/11/2014

Aprovado: 03/02/2015 